\title{
Multi-hazard Groundwater Risks to Water Supply from Shallow Depths: Challenges to Achieving the Sustainable Development Goals in Bangladesh
}

\author{
Mohammad Shamsudduha' ${ }^{1}$ - George Joseph ${ }^{2} \cdot$ Sabrina S. Haque ${ }^{2,3} \cdot$ Mahfuzur R. Khan $^{4} \cdot$ Anwar Zahid $^{5}$. \\ Kazi Matin U. Ahmed ${ }^{4}$
}

Received: 19 September 2019 / Revised: 19 September 2019 / Accepted: 26 September 2019 / Published online: 15 October 2019

(c) The Author(s) 2019

\begin{abstract}
Groundwater currently provides $98 \%$ of all drinking-water supply in Bangladesh. Groundwater is found throughout Bangladesh but its quality (i.e., arsenic and salinity contamination) and quantity (i.e., water-storage depletion) vary across hydrological environments, posing unique challenges to certain geographical areas and population groups. Yet, no national-scale, multi-parameter groundwater hazard maps currently exist enabling water resources managers and policy makers to identify vulnerable areas to public health. We develop, for the first time, groundwater multi-hazard maps at the national scale of Bangladesh combining information on arsenic, salinity, and water storage. We apply geospatial techniques in ' $\mathrm{R}$ ' programming language and ArcGIS environment, linking hydrological indicators for water quality and quantity to construct risk maps. A range of socioeconomic variables including access to drinking and irrigation water supplies and social vulnerability (i.e., poverty) are overlaid on these risk maps to estimate exposures. Our multi-parameter groundwater hazard maps show that a considerable proportion of land area (5-24\% under extremely high to high risks) in Bangladesh is currently under combined risk of arsenic and salinity contamination, and groundwater-storage depletion. As small as 6.5 million (2.2 million poor) to 24.4 million (8.6 million poor) people are exposed to a combined risk of high arsenic, salinity, and groundwater-storage depletion. Our groundwater hazard maps reveal areas and exposure of population groups to water risks posed by arsenic and salinity contamination and depletion of water storage. These geospatial hazard maps can potentially guide policy makers in prioritizing mitigation and adaptation measures in order to achieve the United Nation's Sustainable Development Goals across the water, agriculture, and public health sectors in Bangladesh.
\end{abstract}

Keywords Groundwater · Water supply $\cdot$ Risks to public health $\cdot$ Global change $\cdot$ Bangladesh

Electronic supplementary material The online version of this article (https://doi.org/10.1007/s12403-019-00325-9) contains supplementary material, which is available to authorized users.

Mohammad Shamsudduha

M.Shamsudduha@ sussex.ac.uk

1 Department of Geography, University of Sussex, Falmer, Brighton BN1 9SJ, UK

2 Water Global Practice, World Bank, Washington, DC 20433, USA

3 Rollins School of Public Health, Emory University, Atlanta, GA 30322, USA

4 Department of Geology, University of Dhaka, Dhaka 1000, Bangladesh

5 Bangladesh Water Development Board, Green Road, Dhaka 1205, Bangladesh

\section{Introduction}

Groundwater is the largest store of freshwater that provides drinking, irrigation, and industrial water supplies, globally (Taylor et al. 2013). In Bangladesh, approximately $32 \mathrm{~km}^{3}$ of groundwater is withdrawn annually of which $90 \%$ is used for irrigation, and $10 \%$ for domestic and industrial purposes combined (Fig. 1) that is equivalent to $4 \%$ of global groundwater withdrawal (Hanasaki et al. 2018). However, the sustainability of groundwater resources is threatened by hydrological and socioeconomic factors such as poor water quality, over-abstraction, inadequate governance, and impacts of changing climate that are not well understood. Effective management of groundwater resources is critical in meeting national and international agenda for improved 
Fig. 1 Groundwater withdrawal (in million cubic meters) combined estimated irrigation and domestic usages in Bangladesh. Groundwater use for irrigation is estimated using the information on number of irrigation wells (dry season of 20152016), both shallow and deep and the irrigated area. Domestic water use is estimated using the number of population in each district (2011 census data) and applying a daily rate of $50 \mathrm{~L}$ per capita usage

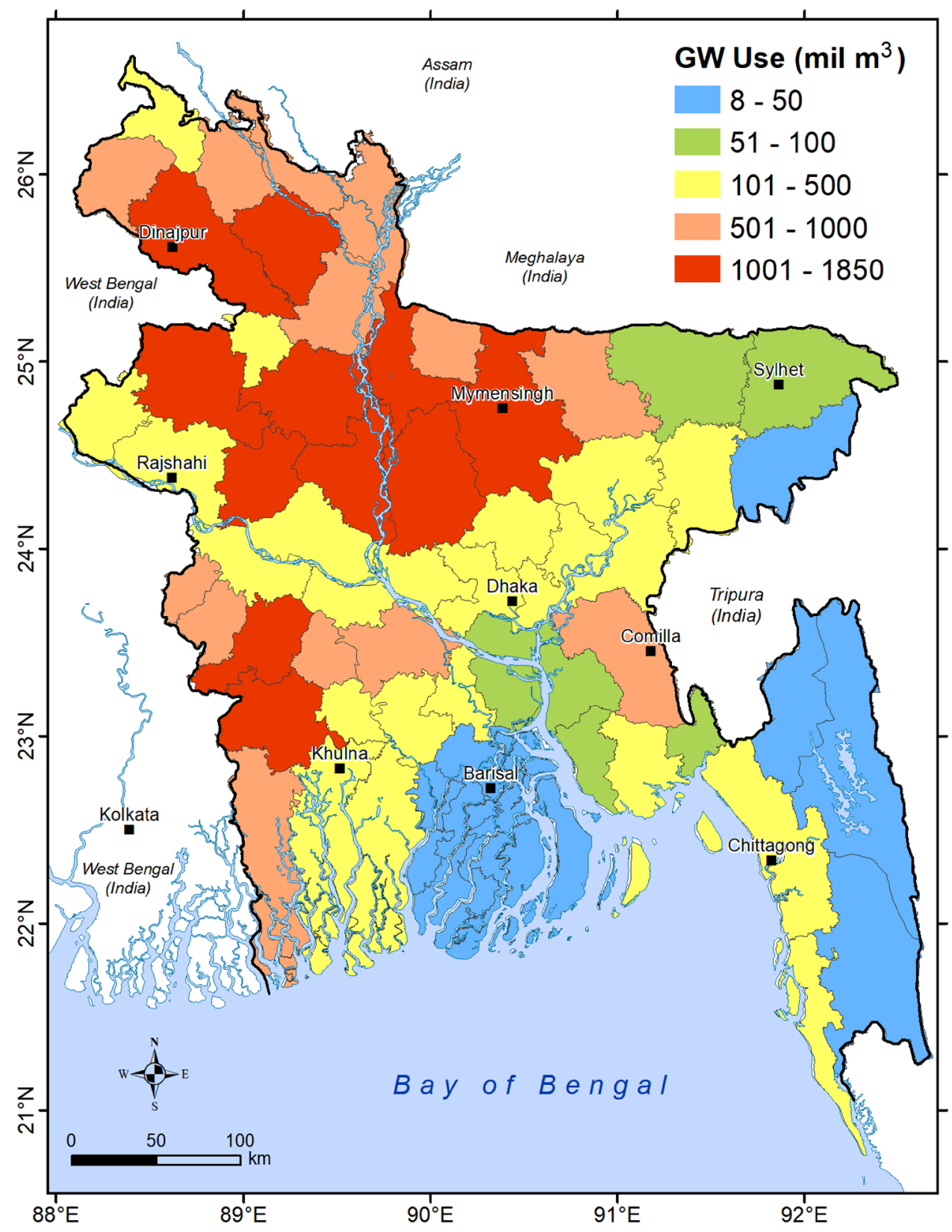

public health, economic development, and poverty alleviation (Conti et al. 2016).

For example, Bangladesh's progress in providing nearly universal access to technologically "improved" drinkingwater supply according to the Millennium Development Goals (MDGs) can mostly be credited to switching from highly-polluted surface water sources to groundwater sources (Hasan et al. 2019). The MDGs, however, did not monitor critical dimensions of safe drinking water such as water quality, convenience, and continuity of service (World Bank 2018). Unsafe water supply is still a leading cause of mortality and morbidity, accounting for at least 1.23 million deaths and 64 million disability-adjusted life years (DALYs) per year (Stanaway et al. 2018). The majority of the burden is from the onset of diarrheal diseases and other enteric infections. Interventions that improve household drinkingwater quality are generally effective in reducing diarrheal disease (Clasen et al. 2015; Fewtrell et al. 2005; Wolf et al. 2018). However, with the exception of continuous, onpremise piped water supply, there is no strong evidence to suggest that gains in improved water coverage will lead to health gains in low- and middle-income countries (LMICs) (Clasen et al. 2015; Wolf et al. 2018). This is likely because improved water structures cannot reliably guarantee water free of fecal and chemical contaminants. The UN estimates that at least $27 \%$ of the population relies on some level of 
fecal or chemical contamination despite most countries meeting MDG water targets of improved water coverage. Rates of contamination are highest in rural regions of least developed countries (WHO/UNICEF 2019). However, the UN's 2030 Agenda for Sustainable Development revises water targets to meet "safely managed water" criteria, where households have access to a technologically improved water source that is available on premise, free of bacterial and chemical contaminants, and available when needed. The revision to the water targets is intended to maximize public health benefits of water infrastructure improvements and helps meet other Sustainable Development Goals (SDGs) such as ending preventable deaths among under-five children by 2030 (Das et al. 2019).

In Bangladesh, about $98 \%$ of drinking and $80 \%$ of dryseason irrigation water supplies come from groundwater at shallow depths $(<150 \mathrm{~m}$ below ground level, bgl) (Shamsudduha 2018). However, widespread arsenic (As) contamination of shallow aquifers affects some $26 \%$ of all tubewells across Bangladesh (UNICEF and BBS 2015; World Bank 2018), making it the largest mass poisoning of a population in history (Smith et al. 2000). Furthermore, a national waterquality assessment estimates that nearly $40 \%$ of all tubewells are contaminated with indicators of fecal bacteria (UNICEF and BBS 2015; World Bank 2018). In some areas of the coast, shallow parts of the Bengal Aquifer System (Burgess et al. 2010) are also subject to increasing salinization in groundwater as a result of sea-level rise, coastal storm-surge inundation, changes in land use, and intensive pumping for water supplies (Ayers et al. 2016; Khan et al. 2014; Shamsudduha 2018). Additionally, shallow groundwater levels in the northwestern, north central, and southwestern areas of the country are declining over time, particularly affecting public water supplies during the dry season when there is notable groundwater abstraction for irrigation (Shamsudduha et al. 2009, 2012).

Sourcing groundwater from deep aquifers has become an effective and popular mitigation strategy to improve drinking-water supply over the last couple of decades for both As and even salinity water-quality issues (Burgess et al. 2010; van Geen et al. 2016). According to the 2011 Bangladesh Census, 31 million households have access to groundwater supplies via tubewells, dugwells, and piped water taps (BBS 2015). The current number of privately owned tubewells is approximately 17 million, compared to a previous estimate of 6-11 million in the early 1990s (BGS and DPHE 2001). In addition to these private wells, additional 1.6 million public tubewells have been installed by the Department of Public Health Engineering of Bangladesh in order to provide As-free drinking-water supply in rural areas. About 20\% of these wells are considered deep ( $>150 \mathrm{mbgl}$ ) wells (DPHE 2016). However, there are concerns of potential contamination of deep groundwater due to ingress of As and salinity from shallow depths (Shamsudduha et al. 2018). Further, improper well-sitting has been documented during extensive deep tubewell installation campaigns (Mondal et al. 2014; van Geen et al. 2016). Contrary to these hydrological concerns, Ravenscroft and others (Ravenscroft et al. 2013) advocate that the development of deep groundwater in Bangladesh is needed. Although it may lead to unsustainable exploitation over the long-term, it will lessen the burden of crippling disease and death from As and salinity contamination of shallow groundwater and surface water while also benefiting future generations by improving public health, education, and economic conditions.

Assessment of groundwater hazards (i.e., natural contamination, depletion) in Bangladesh has been conducted previously but in isolation. For instance, using various geospatial techniques within the Geographic Information System (GIS) platform population risks to groundwater arsenic was mapped at local to national scales in Bangladesh (Hassan and Atkins 2007; Khan and Bakar 2019). Hazard maps of groundwater salinity in Bangladesh are, however, limited to coastal region where saline levels are greatest in shallow groundwater (Zahid et al. 2013). Groundwater-storage maps (Shamsudduha et al. 2009) are conducted as individual hazard in relation to risks to drinking and irrigation water supplies. To date, integrated, multi-parameter groundwater hazard mapping has not been conducted at the national scale to guide water resources officials and policy makers in Bangladesh. It is suggested that sustainable groundwater-fed water supplies critically depend on both quality and quantity (MacDonald et al. 2016). We, therefore, argue that multiparameter groundwater hazard maps combining information on both water quality (e.g., arsenic, salinity) and quantity (e.g., storage depletion) are more useful than individual hazard maps as policy makers and water managers can identify priority areas with multiple hazards and population exposure. For example, interventions for mitigating arsenic can also help reduce population exposure to high salinity and pathogens, as multiple water-related hazards can be present in the same area as revealed in a recent study (Mondal et al. 2014). As the new era of the United Nation's Sustainable Development Goals (SDGs) has begun, Bangladesh needs to look beyond improved access to 'improved and safe drinking water supply' in order to address water quality (SDG 6.3: improve water quality by reducing pollution) and water sustainability (SDG 6.4: ensure sustainable withdrawals and supply of freshwater to address water scarcity). Strategies in meeting these integrated targets can benefit from geospatial analysis of layers of digital data on groundwater quality and quantity in Bangladesh as identified in a recent policy research (Shamsudduha et al. 2019).

Here, we develop, for the first time, multi-parameter groundwater hazard maps for Bangladesh incorporating three hydrological indicators: groundwater arsenic, salinity, 
(a)

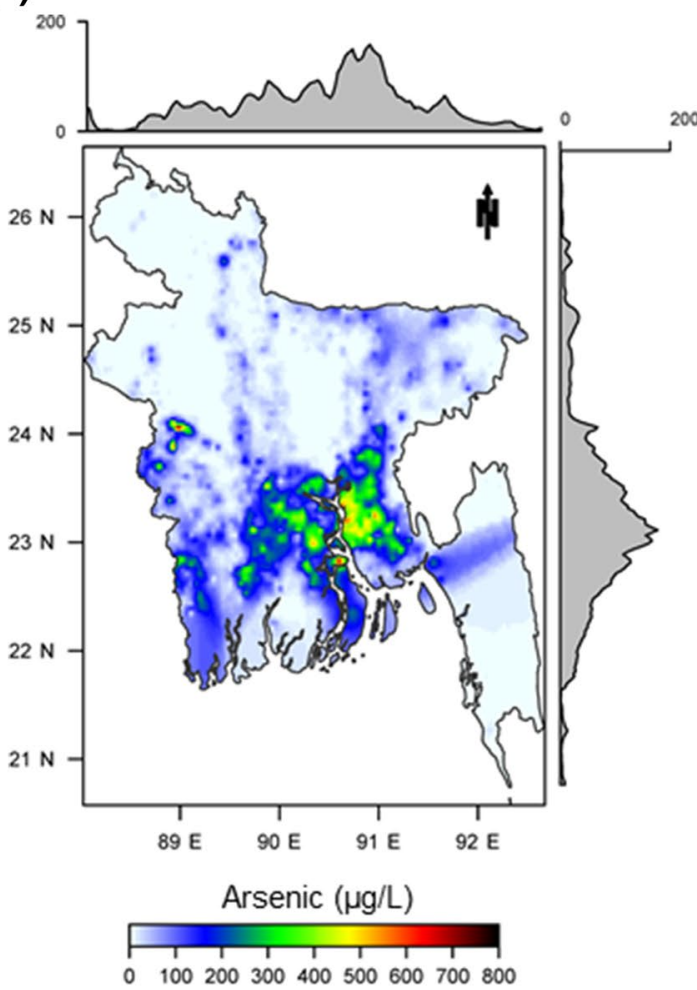

(b)

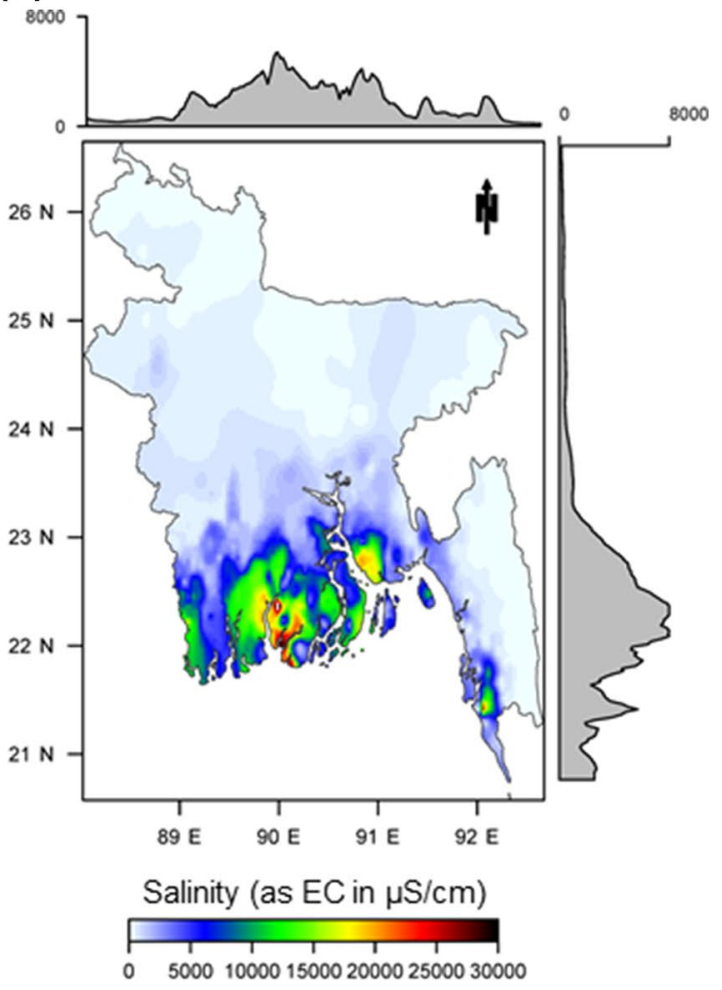

(c)

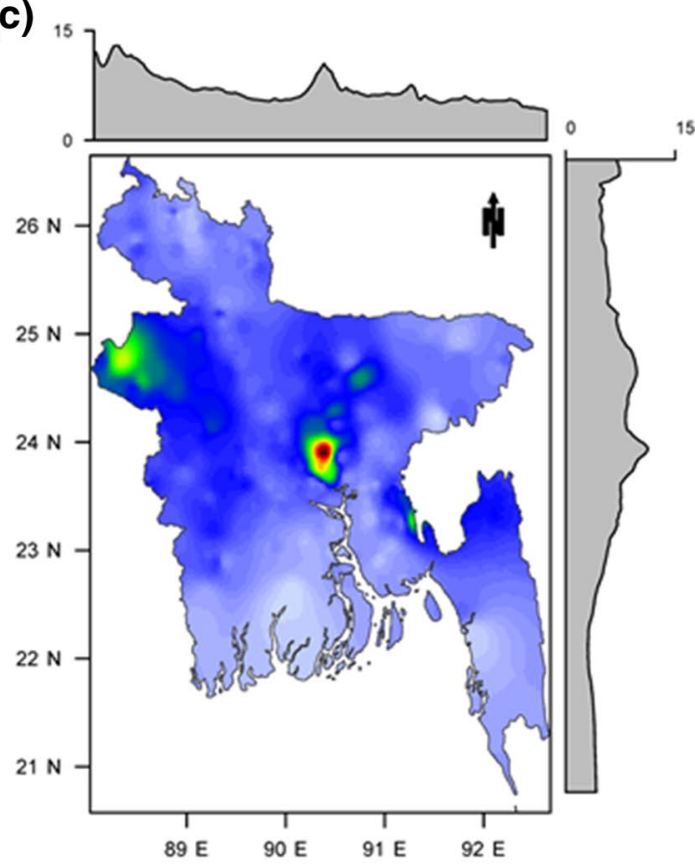

Groundwater depth ( $\mathrm{mbgl})$

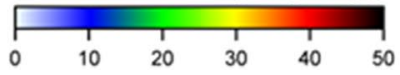

Fig. 2 Groundwater hydrological parameters used to develop groundwater multi-hazard maps for Bangladesh: a arsenic concentrations in shallow groundwaters, b groundwater salinity (i.e., electrical conductivity), and $\mathbf{c}$ depth to dry-season groundwater levels. Hydrologi- cal parameters are interpolated at the national scale. The additional gray-color filled line graphs on top and right margins represent mean values of interpolated grids along the columns and rows of the raster datasets of the interpolated parameters 
and water storage. Our national-scale maps identify critical areas across the entire Bangladesh that may have both groundwater quality (arsenic and salinity contamination) and quality (groundwater-storage decline) issues-affecting access to drinking and irrigation water supplies. We have estimated exposure of population groups, particularly poor and socially vulnerable population, number of households with access to tubewells and piped water supplies, and the access to irrigation water supply to various levels of groundwater risks. These groundwater multi-hazard maps, and associated hydrological information and data will be made publicly available so that additional water-related indicators (e.g., E. coli, access to sanitation services) can be incorporated to the models in future to develop further these national-scale groundwater risk maps to estimate population exposure.

\section{Materials and Methods}

Water-related multi-parameter groundwater hazard mapping at the national scale of Bangladesh is conducted in this study that applies a number of hydrological indicators or variables such as (i) shallow groundwater arsenic (As) concentrations, (ii) groundwater salinity [i.e., Electrical Conductivity (EC) of shallow groundwater], and (iii) the mean depth (2004-2013) to dry-season (December-April) groundwater levels (GWD) as an indicator of groundwater-storage depletion. A brief description of the hydrological data is provided here but a broader description can also be found in the supplementary text.

\section{Arsenic Concentrations in Groundwater}

We use groundwater arsenic (As) dataset from the nationalscale survey of groundwater in Bangladesh (National Hydrochemical Survey) that was conducted jointly by the British Geological Survey (BGS) and the Department of Public Health Engineering (DPHE) (BGS and DPHE 2001). According to the national hydrochemical survey, nearly $90 \%$ of these surveyed wells have an intake depth of $<150 \mathrm{mbgl}$ and are considered shallow wells (see Supplementary Texts for further details). Approximately $25 \%$ of these shallow tubewells were drawing groundwater with As concentrations $>50 \mu \mathrm{g} / \mathrm{L}$ (Bangladesh drinking-water standard); nearly $42 \%$ of these wells were recorded to contain As concentrations $>10 \mu \mathrm{g} / \mathrm{L}$ (WHO drinking-water standard). Our analysis applies interpolated As concentrations (Fig. 2a) for developing groundwater risk maps at the national scale in Bangladesh. Arsenic concentrations at geographic points $(n=3207)$ were interpolated using the Inverse Distance Weighting (IDW) algorithm and resampled at $2.5-\mathrm{km} \times 2.5-\mathrm{km}$ grid resolution using the 'raster' package in the ' $R$ ' programming language ( $R$ Core Team 2017).

\section{Groundwater Salinity: Electrical Conductivity}

Elevated groundwater salinity is common at shallow depth $(<150 \mathrm{mbgl})$ in coastal aquifers of southern Bangladesh and is generally defined by total dissolved solids (TDS), or Electrical Conductivity (EC) or chemical constituent such as chloride (Cl) (Zahid et al. 2013). There is no national-scale, frequent (e.g., monthly) monitoring of groundwater salinity in Bangladesh. Over the years, a few studies (see Supplementary Texts for further details) have generated some contour maps of groundwater EC at the national scale but there is little detail on the datasets used for mapping. Here, we have generated a groundwater EC map at the national scale using data primarily from two sources. First, we collated groundwater EC data from 461 newly installed monitoring boreholes that were installed recently under a regionalscale hydrogeological study conducted in 19 coastal districts by the Bangladesh Water Development Board (BWDB) (BWDB 2013). Second, we have digitized and georeferenced the contoured map of groundwater EC (Rahman and Ravenscroft 2003) and extracted point data of EC at 102 locations throughout the country, predominantly in the northern part where there are limited groundwater EC measurements as groundwater is generally fresh. Finally, we interpolated the point data $(n=563)$ at the national scale using the IDW algorithm in ArcGIS environment. The interpolation error was $50 \mu \mathrm{S} / \mathrm{cm}$ compared to the data range of $27-43,950 \mu \mathrm{S} / \mathrm{cm}$ with a mean of $5251 \mu \mathrm{S} / \mathrm{cm}$. We then rasterized, using the ' $\mathrm{R}$ ' programming language, the interpolated EC data at a grid resolution of $2.5-\mathrm{km} \times 2.5-\mathrm{km}$ (Fig. $2 \mathrm{~b}$ ).

\section{Depth to Dry-Season Groundwater Levels}

We use mean depth to dry-season (December-April) groundwater levels as a hydrological indicator for representing groundwater-storage depletion in Bangladesh. This is an important measure of sustainability of shallow groundwater abstraction in Bangladesh using low-lift pumps, for example, the No. 6 hand-operated pump, which is widely used for drinking and domestic purposes (see Supplementary Texts for further details). Mean depths to dry-season groundwater levels were estimated from weekly monitoring records from 236 boreholes from 2004 to 2013 (Fig. 2c). These monitoring boreholes belong to a network of some 1250 monitoring wells across the entire country that have been managed by the Bangladesh Water Development Board (BWDB) since the early 1960s. We estimated depth to mean dry-season groundwater levels (i.e., maximum depth below ground level) using the ground surface as a reference level. 


\section{Demography, Access to Water Supply, and Social Vulnerabilities}

Demographic datasets on population, poverty, tubewells, and access to pipe water supplies in Bangladesh at the upazila level are collated from a GIS database (The Bangladesh Interactive Poverty Maps) published by the World Bank (2016). The country-level demographic database allows one to explore and visualize socioeconomic data at both Zila (district) and Upazila (sub-district) level. The online GISbased mapping tool enables an easy access to different types of indicators including poverty, demographics of the population, children's health and nutrition, education, employment, and household access to energy, water, and sanitation services (World Bank 2016). These maps (see maps in supplementary Figure S1) were constructed by combining three different data sources all of which are publicly available: (i) 2010 Bangladesh Poverty Maps, (ii) 2011 Bangladesh Census of Population and Housing, and (iii) 2012 Undernutrition Maps of Bangladesh (BBS/WFP/IFAD 2012). Children's health and nutrition datasets were produced by the World Food Program (WFP) and are constructed based on data from the Child and Mother Nutrition Survey of Bangladesh 2012 (MICS) and the Health and Morbidity Status Survey 2011 (HMSS).

Upazila-level total population and percentage of poor population (i.e., percentage of the population that lives below the official national upper poverty line, which is based on household's poverty status assessed using per capita consumption) are shown in Figure S1. According to the 2011 National Population Census, conducted by the Bangladesh Bureau of Statistics, the total population of the country was 144 million with $76 \%$ of the total population live in rural areas in Bangladesh (see Supplementary Texts for further details)

Upazila-level, percentage of households with access to tubewell and tapwater supplies in Bangladesh are shown in Figure S2. The data on access to water supply come from the 2011 Census of Population and Housing. The national average of households with an access to tubewell and tapwater supply (town or municipal water supply via piped network) is $82 \%$ and $10 \%$, respectively. Tapwater supply is limited to provincial towns and large metropolitan cities such as Dhaka, Chittagong, Rajshahi, Sylhet, Barisal, and Rangpur (Fig. 1).

Access to groundwater-fed water supplies for irrigation is an important indicator for measuring food security in Bangladesh. Upazila-level, groundwater use for irrigation for the year of 2006-2007 Boro rice season is shown in Figure S2c. Groundwater irrigation has been estimated using reported information on irrigated area and the number of irrigation pumps surveyed under the minor irrigation campaign by the Bangladesh Agricultural Development Corporation
(BADC). Additional information on irrigation requirement for dry-season rice cultivation under various soil types and their infiltration capacity (Ravenscroft 2003) has been used to estimate groundwater irrigation.

The social vulnerability is defined here by the lack of nutrition in children under the age of five. Four indicators measuring the level of undernutrition in children: the number of underweight and severely underweight, and stunted and severely stunted children at the upazila level of Bangladesh (Figure S3) are used here to characterize social vulnerabilities. According to the 2012 Undernutrition Maps of Bangladesh, underweight and severely underweight children are those, whose standardized weight-for-age is less than two and three standard deviations, respectively, below the median for the international reference following the WHO standard. Similarly, stunted and severely stunted children are those, whose standardized height-for-age is less than two and three standard deviations, respectively, below the median for the international reference following the WHO standard.

\section{Groundwater Risks Mapping at the National Scale}

We construct two multi-hazard groundwater hazard maps based on the following selection criteria applying on groundwater arsenic (As), salinity (i.e., electrical conductivity, EC), and dry-season depth to shallow groundwater levels (GWD) at the national scale in Bangladesh. Mapped areas of groundwater risks represent four zones with specific ranges of groundwater As and salinity concentrations that are considered risks to public health, and depth to dry-season groundwater levels below or greater than a certain threshold (4-8 m bgl) that is considered unsustainable to low-lift pumping technologies and economically expensive. Cut-off values of hazard parameters such as arsenic, salinity, and groundwater depletion are based on various drinking-water standards and lifting capacity of traditional pumping technologies used in Bangladesh. For instance, drinking-water standards for arsenic are $10 \mu \mathrm{g} / \mathrm{L}$ and $50 \mu \mathrm{g} / \mathrm{L}$ according to the World Health Organization (WHO) and Bangladesh Government guidelines, respectively. There are no Bangladesh standards for salinity in drinking water; however, according to the WHO the "palatability of water with a total dissolved solids (TDS) level of less than about $600 \mathrm{mg} / \mathrm{L}$ is generally considered to be good" (WHO 2011). According to the secondary drinking-water guidelines by the US Environmental Protection Agency's (EPA 2018), the drinking-water standard for TDS is $500 \mathrm{mg} / \mathrm{L}$ that is equivalent to $\sim 750 \mu \mathrm{S} / \mathrm{cm}$ of electrical conductivity (EC) considering a ratio of 0.65 between TDS and EC (Rusydi 2018). Finally, the maximum lifting capacity of hand-operated pumps in Bangladesh is 7-8 m below ground level (bgl) (UNICEF 2010). We consider two threshold-based multi-hazard risk modeling of groundwater into four categories: extremely high, high, medium, and low 
risks. An area is classified as at risk (ranging from extremely high to low) based on the levels of multiple hazards being present over a certain threshold as listed below.

Groundwater multi-hazard map is based on the following criteria (model 1) for four risk categories:

- Extremely high risk: As $>100 \mu \mathrm{g} / \mathrm{L} \& \mathrm{EC}>1500 \mu \mathrm{S} / \mathrm{cm}$ \& GWD $>8 \mathrm{~m}$ bgl

- High risk: As $>50 \mu \mathrm{g} / \mathrm{L}$ \& EC $>750 \mu \mathrm{S} / \mathrm{cm} \&$ GWD $>6 \mathrm{~m} \mathrm{bgl}$

- Medium risk: As $>10 \mu \mathrm{g} / \mathrm{L} \& \mathrm{EC}>750 \mu \mathrm{S} / \mathrm{cm}$ \& GWD $>5 \mathrm{~m} \mathrm{bgl}$

- Low risk: As $>10 \mu \mathrm{g} / \mathrm{L} \& \mathrm{EC}>500 \mu \mathrm{S} / \mathrm{cm} \& \mathrm{GWD}>4 \mathrm{~m}$ bgl.

Groundwater multi-hazard map is based on the following criteria (model 2) for four risk categories:

- Extremely high risk: As $>100 \mu \mathrm{g} / \mathrm{L} \& \mathrm{EC}>1500 \mu \mathrm{S} / \mathrm{cm}$

- High risk: As $>50 \mu \mathrm{g} / \mathrm{L} \& \mathrm{EC}>750 \mu \mathrm{S} / \mathrm{cm}$

- Medium risk: As $>10 \mu \mathrm{g} / \mathrm{L} \& \mathrm{EC}>750 \mu \mathrm{S} / \mathrm{cm}$

- Low risk: $\mathrm{As}>10 \mu \mathrm{g} / \mathrm{L} \& \mathrm{EC}>500 \mu \mathrm{S} / \mathrm{cm}$.

Groundwater multi-hazard maps are generated using the above sets of criteria in ' $\mathrm{R}$ ' programming language ( $\mathrm{R}$ Core Team 2017). First, raster maps of spatial grid resolution of $2.5-\mathrm{km} \times 2.5-\mathrm{km}$ for the three hydrological risk variables are generated using the Inverse Distance Weighting (IDW) algorithm in ESRI's ArcGIS environment (software version 10.3.1). Raster datasets are imported into ' $R$ ' statistical software environment and the above sets of criteria are applied to individual grid point (total number of grids: 19,613 covering an area of $\sim 148,000 \mathrm{~km}^{2}$ ).

\section{Results}

\section{Groundwater Multi-hazard Mapping at National Scale}

A composite groundwater multi-hazard map (Fig. 3) in red, green, and blue (RGB) colors represents, a combination of three hydrological indicators such groundwater arsenic concentration (green), salinity or groundwater EC (blue), and depth to dry-season groundwater levels (red) in Bangladesh. The composite map clearly shows that the northwestern and northcentral Bangladesh is featured by deep dry-season groundwater levels, whereas arsenic problem in shallow groundwater is mainly concentrated in southcentral region, and the southern, coastal region of Bangladesh has the highest level of groundwater salinity. The composite map clearly highlights the areas where more than one hydrological indicator or risk variable (i.e., high arsenic and high salinity; or high arsenic and deep groundwater levels; or a combination of all three elements) exists to a varying degree.

\section{Groundwater Risks to Population Exposure}

Two groundwater multi-hazard maps for Bangladesh using two sets of combination criteria (model 1: groundwater arsenic, salinity and storage; model 2: groundwater arsenic and salinity) are shown in Fig. 4. Each groundwater risk map has four classes: extremely high risk, high risk, medium risk, and low risk that are based on a set of criteria (models) described in the method section. In addition, groundwater risks posed by arsenic and salinity alone are mapped considering various concentrations of arsenic and electrical conductivity in water (see risk maps in supplementary Figures S7 and S8).

Groundwater multi-hazard map under model 1 (Fig. 4a), the mapped area $\left(208 \mathrm{~km}^{2}\right.$; Table 1$)$ within the zone of extremely high risk, is small and located mainly in central Comilla district of the southeastern part of Bangladesh (Fig. 4a). There are some 219,193 (0.15\% of total population) people exposed to the extremely high risk of groundwater (Table 2). The high-risk zone covers a large area of $7146 \mathrm{~km}^{2}$ (5.3\% of total land area) from southwestern to southeastern Bangladesh encompassing a number of districts such as Satkhira, Jessore, Narail, Fardipur, Dhaka, Munshiganj, Comilla, Feni, and Chittagong where some 6.4 million $(4.4 \%)$ people are exposed to groundwater risks. The medium-risk zone covers a larger area of $10,350 \mathrm{~km}^{2}(7 \%)$ over most part of the Ganges-Brahmaputra-Meghna delta except for the exposed coastal region and about 9.5 million (6.6\%) people are exposed to medium groundwater risks. Combined population of approximately 16 million (11\%) are currently at variable risk (extremely high to medium risk) of elevated arsenic, salinity, and depth to dry-season groundwater levels. Lastly, the mapped zone under low risk in model 1 covers an area of $28,123 \mathrm{~km}^{2}(20 \%)$ where 21 million (15\%) people are currently at combined low risk of arsenic, salinity, and groundwater-storage depletion.

Groundwater multi-hazard map under model 2 (Fig. 4b), the mapped area within the zone of extremely high risk, is substantial $\left(18,297 \mathrm{~km}^{2} ; 13 \%\right.$ of total land area) and it covers most part of southeastern Bangladesh where nearly 13 million (9\% of total population) people are exposed (Tables 1,2). The high-risk zone covers an area of $15,147 \mathrm{~km}^{2}(11 \%)$ and an estimated 12 million (8\%) people are currently exposed. The medium-risk zone covers an area $13,160 \mathrm{~km}^{2}(9 \%)$ and an estimated 9 million (6\%) people are currently exposed. Finally, an estimated land area of $18,797 \mathrm{~km}^{2}(13 \%)$ and 13 million (9\%) people are located in an area where there is low groundwater risk due to relatively less contamination of arsenic and salinity. Considering arsenic and salinity individually, we find that approximately 33 million (23\% of total population) people 
Fig. 3 A national-scale RGB (red-green-blue) color composite map of the three groundwater hazards: storage decline as indicated by the depth to dryseason groundwater levels (red), arsenic concentrations in shallow groundwaters (green), and groundwater salinity hazard as indicated by electrical conductivity (blue). The scale of each side of the triangle represents the range (minimum as 0 to maximum as $100 \%$ ) of values for each hydrological parameter as shown in Fig. 2

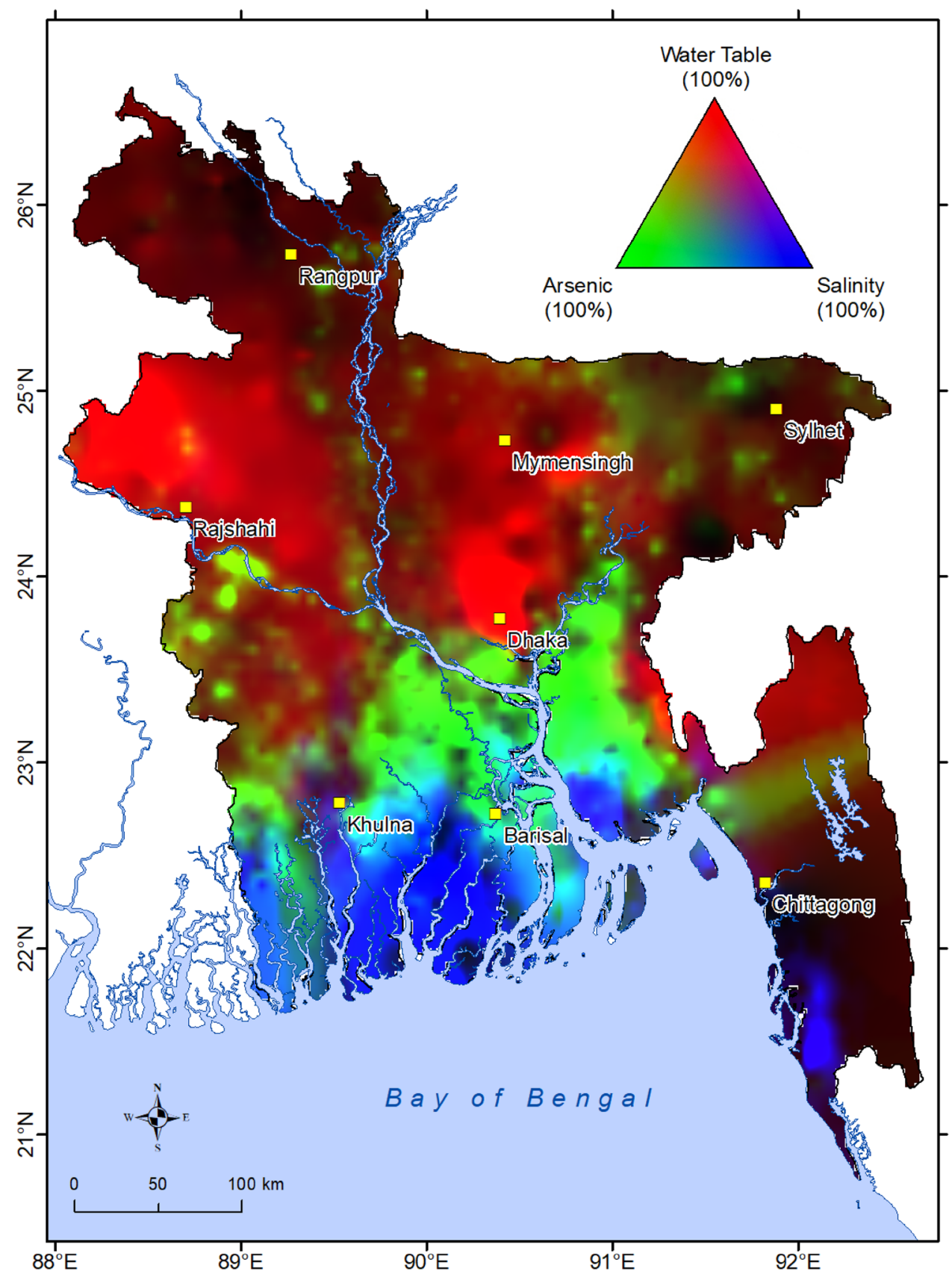

are currently at variable risk of elevated ( $>50 \mu \mathrm{g} / \mathrm{L})$ arsenic, and nearly 26 million (18\%) are exposed to very high $(>1500 \mu \mathrm{S} / \mathrm{cm}$ ) salinity in shallow groundwater.

\section{Groundwater Risks to Access to Drinking and Irrigation Water Supplies}

In addition to demographics of population, we estimate exposure of poor people and household access to water supplies within the mapped groundwater risk zones under both models. Results are summarized in Tables 1 and 2 .
Groundwater risk mapping reveals that 3-6 million households with an access to tubewells are currently at risk of various degrees under models 1 and 2, respectively. Furthermore, an estimated 237-418 thousand households with an access to tapwater supply are at risk of arsenic and salinity contamination as well as depletion of shallow groundwater. However, this is noteworthy that tapwater supplies in towns and metropolitan cities often derive from deep groundwater that may not be at immediate risk to arsenic or salinity contamination. 


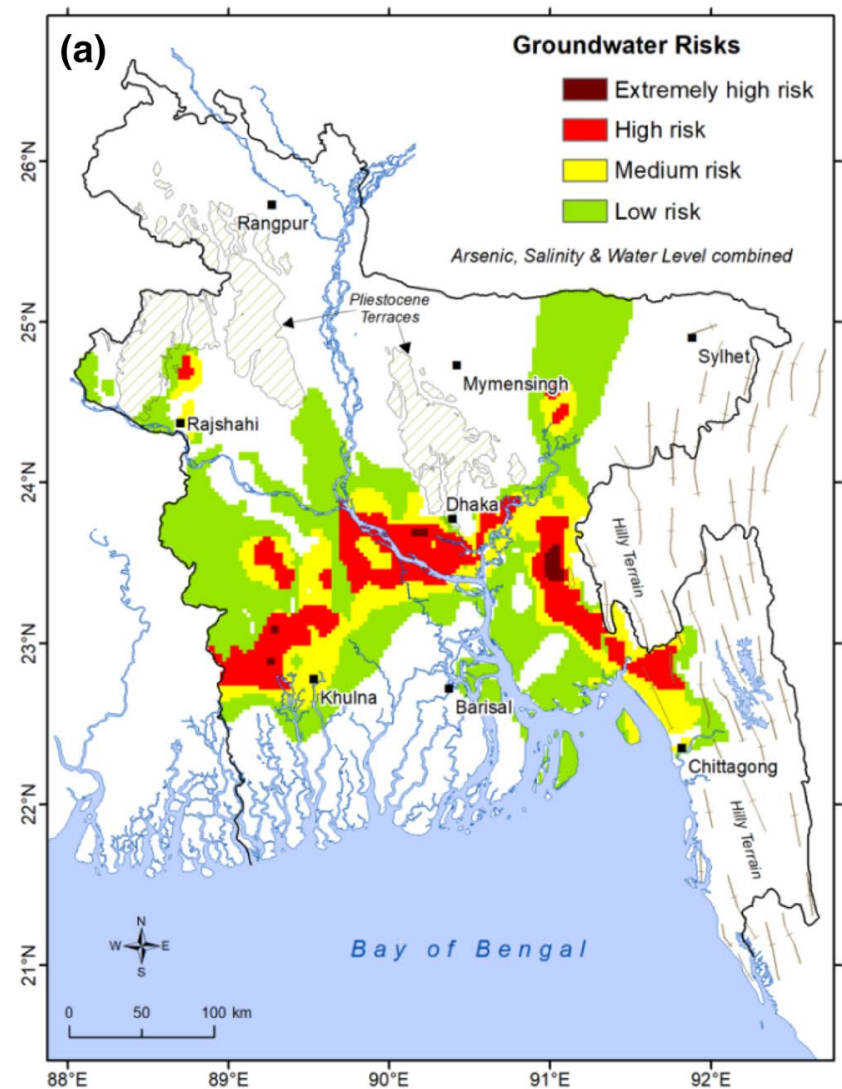

Fig. 4 Groundwater risk maps at the national scale in Bangladesh: a groundwater risk map based on model 1 (arsenic, salinity, and dryseason groundwater levels); b groundwater risk map based on model 2 (arsenic and salinity only). Both maps show four zones: extremely

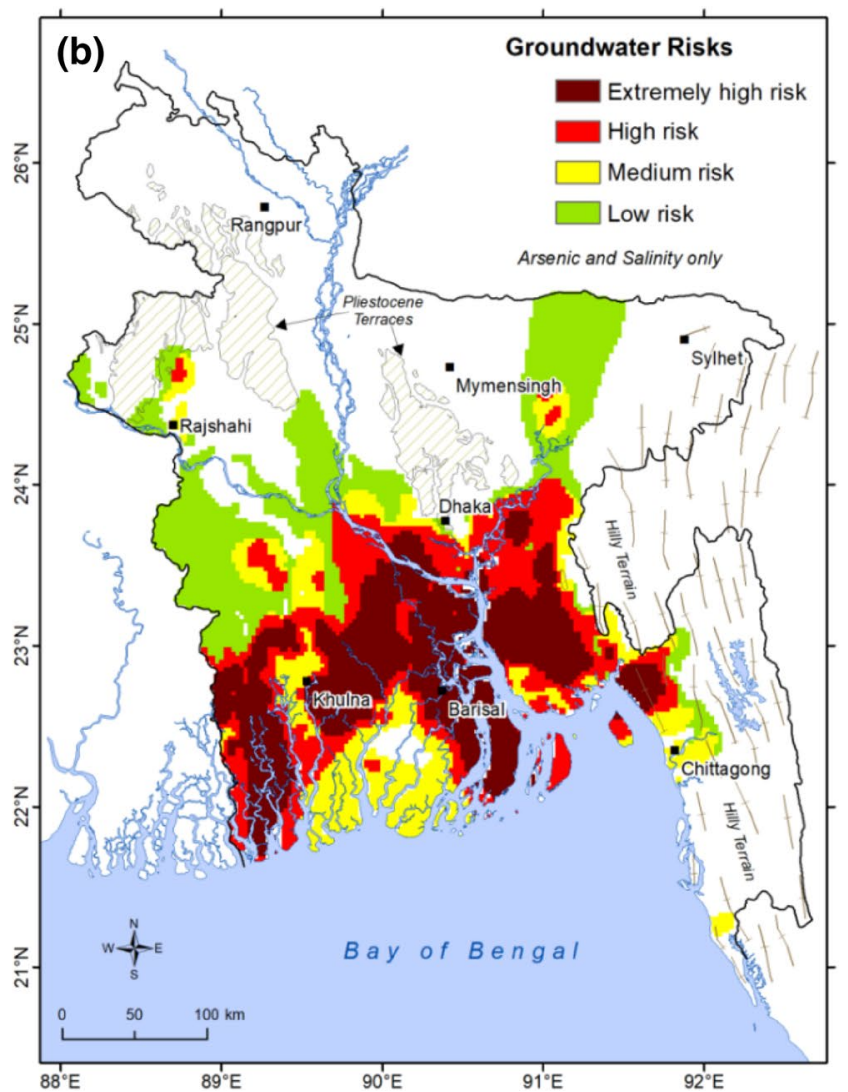

high, high, medium, and low risks to shallow groundwater based on a combination of two or three parameters above some threshold values described in the method. Maps of higher resolution are provided in the supplementary information
Table 1 Summary statistics number of grids used in the groundwater multi-hazard risk mapping at the national scale in Bangladesh; area covered under four risk zones under each risk model

\begin{tabular}{lcccc}
\hline Risk zone & No. of grids & Area $\left(\mathrm{km}^{2}\right)$ & $\begin{array}{l}\text { Cumulative area } \\
\left(\mathrm{km}^{2}\right)\end{array}$ & $\begin{array}{l}\text { Proportion of cumu- } \\
\text { lative land area (\%) }\end{array}$ \\
\hline Groundwater risk map (model 1: arsenic, salinity and groundwater storage) \\
Extremely high risk & 27 & 208 & 208 & 0.15 \\
High risk & 955 & 7146 & 7354 & 5.26 \\
Medium risk & 2299 & 10,350 & 17,704 & 12.66 \\
Low risk & 5951 & 28,123 & 45,826 & 32.78 \\
Groundwater risk map (model 2: arsenic and salinity only) & & \\
Extremely high risk & 2376 & 18,297 & 18,297 & 13.09 \\
High risk & 4343 & 15,147 & 33,444 & 23.92 \\
Medium risk & 6052 & 13,160 & 46,604 & 33.33 \\
Low risk & 8493 & 18,797 & 65,401 & 46.78 \\
\hline
\end{tabular}

\section{Groundwater Risks to Socially Vulnerable Population}

Our analysis shows that poor people are exposed to groundwater risks at various degrees. According to groundwater risk map (model 1 ), there are approximately 5 million poor people who are currently exposed at various degrees of risks with a potential of another 6 million poor people being affected in future. Groundwater multi-hazard map and assessment of risk based on model 2 show greater number of poor people (11 million) are currently exposed to shallow groundwater with elevated arsenic and salinity 
Table 2 Summary statistics of demographics of the population, poverty, and social vulnerability levels, and household and irrigation access to water supplies in Bangladesh that are under various degrees

\begin{tabular}{|c|c|c|c|c|}
\hline Variables at risk & Extremely high risk & High risk & Medium risk & Low risk \\
\hline \multicolumn{5}{|c|}{ Groundwater risk map (model 1: arsenic, salinity, and groundwater storage) } \\
\hline Total population ( $\%$ of country total) & $219,193(0.15 \%)$ & $6,361,209(4.4 \%)$ & $9,453,381(6.6 \%)$ & $21,291,790(14.8 \%)$ \\
\hline Poor population & 86,640 & $2,101,933$ & $2,677,818$ & $6,443,670$ \\
\hline Access to tubewells (no. of households) & 41,232 & $1,252,477$ & $1,763,131$ & $4,141,321$ \\
\hline Access to tapwater (no. of households) & 777 & 79,289 & 157,063 & 311,157 \\
\hline No. of people under irrigation water risks & 112,231 & $2,206,011$ & $4,288,679$ & $10,569,615$ \\
\hline No. of underweight children & 9740 & 229,192 & 547,423 & $1,374,227$ \\
\hline No. of severely underweight children & 2438 & 53,563 & 127,925 & 327,032 \\
\hline No. of stunted children & 10,206 & 274,545 & 659,847 & $1,629,770$ \\
\hline No. of severely stunted children & 5735 & 155,620 & 373,739 & 939,453 \\
\hline \multicolumn{5}{|c|}{ Groundwater risk map (model 2: arsenic and salinity only) } \\
\hline Total population (\% of country total) & $12,766,085(8.9 \%)$ & $11,646,293(8.1 \%)$ & $8,958,893(6.2 \%)$ & $13,431,311(9.3 \%)$ \\
\hline Poor population & $4,800,111$ & $3,838,106$ & $2,276,558$ & $3,852,640$ \\
\hline Access to tubewells (no. of households) & $2,460,107$ & $2,185,143$ & $1,585,841$ & $2,710,915$ \\
\hline Access to tapwater (no. of households) & 88,852 & 122,535 & 206,509 & 209,565 \\
\hline No. of people under irrigation water risks & $1,623,303$ & $4,049,400$ & $5,278,533$ & $10,834,711$ \\
\hline No. of underweight children & 475,340 & 921,537 & $1,205,462$ & $1,707,839$ \\
\hline No. of severely underweight children & 113,746 & 221,445 & 286,543 & 405,216 \\
\hline No. of stunted children & 540,627 & $1,062,574$ & $1,413,476$ & $2,019,439$ \\
\hline No. of severely stunted children & 307,608 & 606,262 & 805,423 & $1,161,879$ \\
\hline
\end{tabular}

Statistics of the same variables are reported under the two groundwater risk models developed in this study. Note that figures under each risk class only refer to exposure within each risk zone and not cumulative

contamination. Our risk analysis shows that 9740 (extremely high risk) to 229,192 (high risk) children are underweight, and 10,206 (extremely high risk) to 274,545 (high risk) children are stunted under the risk model 1 (Table 2). According to the risk model 2, an estimated 475,340 (extremely high risk) to 921,537 (high risk) children are underweight, and 540,627 (extremely high risk) to 1,062,574 (high risk) children are stunted (Table 2).

\section{Discussion}

Bangladesh has made significant progress in addressing food security and public health in the last few decades. Contribution of groundwater resources to economic development, social well-being, and public health has been paramount. Despite the importance of groundwater and its critical role in all sectors including health, no multi-parameter hazard maps for Bangladesh currently exist. The links between adverse human health and long-term exposure to elevated arsenic (As) and salinity concentrations in drinking water are well established in the country. Access to drinking and irrigation water supplies is also affected due to widespread depletion of shallow groundwater storage in various parts of Bangladesh threatening food security. Here, for the first of groundwater risks due to elevated arsenic and salinity contamination and depletion of groundwater storage 
Health Services in Bangladesh (DPHE/JICA 2010) shows that some $18,672(51 \%)$ of the total of 37,039 patients (i.e., primarily skin lesions) are located in areas where $>80 \%$ wells are found to be As contaminated. Overlaying on our groundwater multi-hazard maps, we find that some 1000 (3\% of total patients) to 22,450 (61\%) As-affected patients are located within the extremely high- to high-risk zones (Fig. 5). One of the limitations of our analysis of multihazard-based groundwater risk mapping is that the maps represent an aggregated risk of static levels of arsenic, salinity, and declining groundwater storage. We employ groundwater arsenic data from the National Hydrochemical Survey that was conducted in 1998-1999 with the assumption that As concentration has limited seasonal and temporal variations (Bhattacharya et al. 2011; Dhar et al. 2008) and, at the basin scale, the spatial pattern of background As levels has remained largely unchanged (BBS and UNICEF 2010). Similarly, our groundwater multi-hazard maps represent an average level of salinity though it varies seasonally (Zahid et al. 2013). Our groundwater multi-hazard maps are based on multi-hazard indicators of various levels. Therefore, any area outside of the mapped risk categories may or may not be free from a single hydrological hazard such as elevated arsenic, salinity, or depletion of water storage. For example, an area with high salinity $(>1500 \mu \mathrm{S} / \mathrm{cm})$ but low arsenic $(<10 \mu \mathrm{g} / \mathrm{L})$ is not mapped as groundwater risk as it does not fulfill the set criteria of multi-hazard indicators but considered to be affected by individual hazards.

Our groundwater multi-hazard maps update the current, rather loosely constrained, estimates of population exposure
Fig. 5 Groundwater risk map and exposure of arsenic-affected population in Bangladesh. Upazila-wise number of arsenic-affected patients (i.e., cases of skin lesions) are mapped as solid colors and various groundwater risk zones (under model 1) are superimposed to show the spatial association between the two datasets. Upazilas without any reported arsenic-affected patients or data are left blanked (i.e., white)

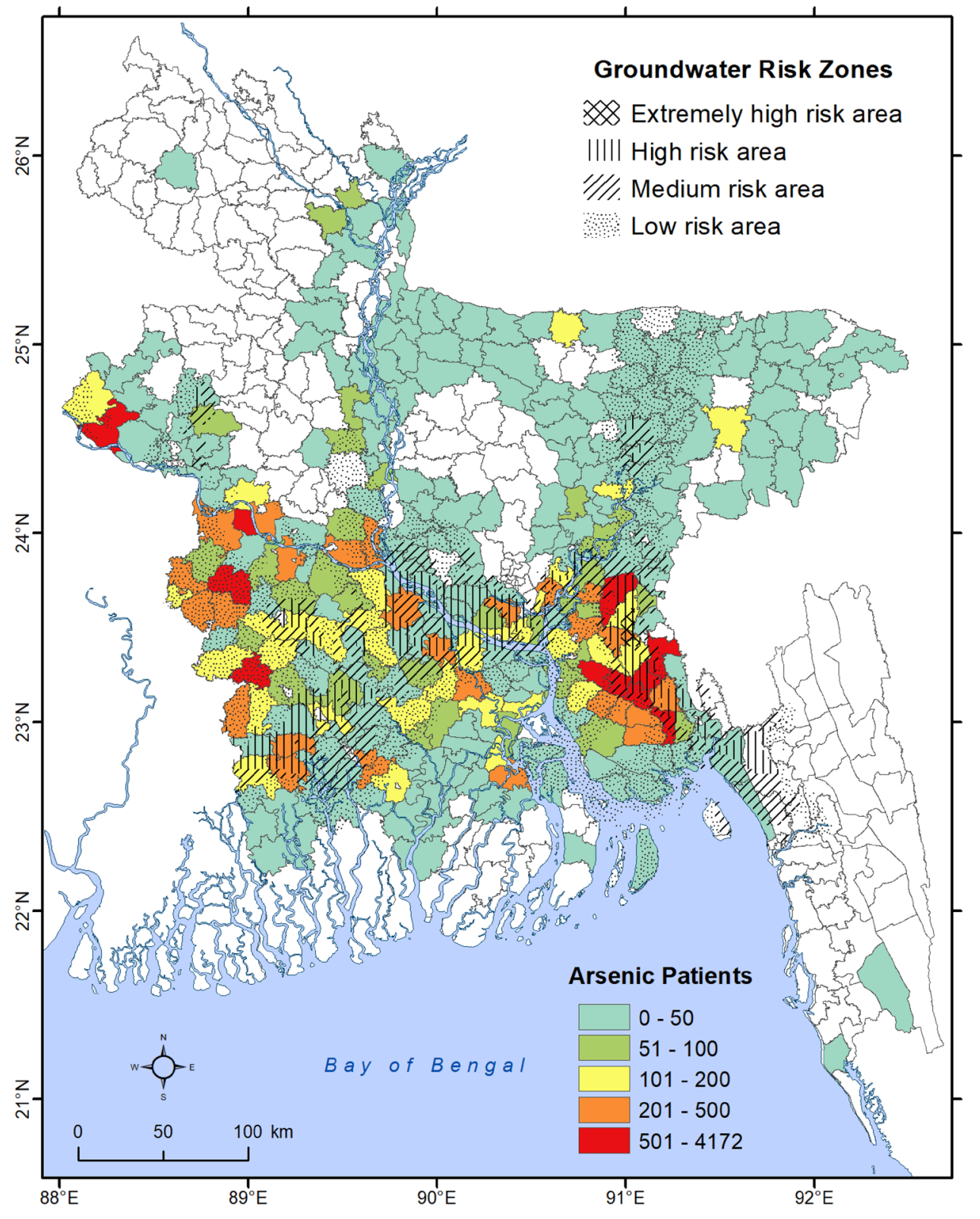


to elevated As and salinity concentrations in Bangladesh. Our groundwater multi-hazard mapping reveals that an estimated 33 (23\% of total population) and 64 (44\%) million people in Bangladesh are currently exposed to As concentrations greater than 50 and $10 \mu \mathrm{g} / \mathrm{L}$ (WHO standard), respectively, in shallow $(<150 \mathrm{mbgl})$ groundwater. Using the groundwater electrical conductivity (EC) map, we estimate that approximately 26 million (18\%) people, predominantly in the coastal region of Bangladesh, are exposed to considerably high salinity $(\mathrm{EC}>1500 \mu \mathrm{S} / \mathrm{cm})$ in groundwater. Our estimate of population exposure to high salinity in groundwater is substantially greater than a previous estimate of 20 million (Khan et al. 2011) people in coastal Bangladesh. Furthermore, the analysis of population exposure to various levels of groundwater risks reveals that approximately $37(26 \%)$ to 47 (33\%) million people are currently at risk to elevated arsenic, salinity, and declined groundwater storage combined that covers 31-44\% land area of Bangladesh. Given the proven public health risk to elevated arsenic and salinity in drinking water and considerable threat to food security associated with depleted water storage, our nationalscale multi-parameter groundwater hazard maps have the potential to guide current practices and policies towards achieving the UN's sustainable development goals in Bangladesh. Additional water-quality hazards (e.g., pathogens) can be incorporated to our mapping framework, as new data are available at the national scale. Finally, our multi-parameter groundwater hazard maps and methods of qualifying risks to exposed populations can be replicated in other Asian mega-deltas where similar groundwater hazards exist.

\section{Conclusions}

We draw the following main conclusions from this nationalscale multi-parameter, groundwater hazard mapping and assessment of risk to population in Bangladesh:

1. Approximately 5\% (risk model 1: arsenic, salinity waterstorage depletion combined) to 24\% (risk model 2: arsenic and salinity) land area in Bangladesh is exposed to extremely high to high risks of elevated arsenic, salinity, and groundwater depletion hazards.

2. An estimated $4.5 \%$ (risk model 1 ) to $17 \%$ (risk model 2) of total population (144 million) of Bangladesh are exposed to extremely high to high risks of elevated arsenic, salinity, and groundwater depletion hazards; $2.2-8.6$ million of these vulnerable populations are poor.

3. Nearly a million (risk model 1) to over 4 million (risk model 2) children, who are exposed to extremely high to high risks of multi-hazard groundwater risks are either underweight or stunted.
4. An estimated $32 \mathrm{~km}^{3}$ of groundwater is withdrawn annually in Bangladesh for irrigation (90\%), and domestic and industrial (10\%) use; this volume is equivalent to $\sim 4 \%$ of global groundwater withdrawals. Furthermore, an estimated 2.3 million (risk model 1) to over 5.7 million (risk model 2) people, who depend on groundwater-fed irrigation are exposed to extremely high to high risks of multi-parameter groundwater hazards.

Finally, we have updated the existing, rather speculative estimates of population exposure to arsenic or salinity contamination individually. Our new estimation using the geospatial risk mapping suggests that nearly 33 million people are exposed to $>50 \mu \mathrm{g} / \mathrm{L}$ (Bangladesh drinking-water standard) of arsenic concentrations, and nearly 26 million are exposed to considerably high (electrical conductivity values $>1500 \mu \mathrm{S} / \mathrm{cm}$ ) salinity in groundwater.

Acknowledgements We acknowledge the kind support provided by the World Bank under a project "Bangladesh WASH (Water, Sanitation and Hygiene) and Poverty Diagnostic" for this work. Support from the Swedish International Development Cooperation Agency and the Japan Trust Fund is acknowledged. We state that the views and recommendations expressed in the paper do not in any way reflect that of the funding bodies. We acknowledge the Bangladesh Climate Change Trust (BCCT) for funding a regional-scale hydrological campaign in coastal region that was carried out by the Bangladesh Water Development Board (BWDB). Finally, we acknowledge the Director General of Health Services (DGHS) of Bangladesh for arsenic-affected population exposure dataset and the Bangladesh Agricultural Development Corporation (BADC) for irrigation dataset.

Author Contributions MS conceived the idea of groundwater risk mapping at the national scale in Bangladesh. MS also designed overall study and prepared groundwater arsenic, salinity, and storage datasets with technical support from AZ. GJ and SSH provided extensive inputs to the preparation of the manuscript and commented on several versions of the text. KMA and MRK have provided arsenic-affected population exposure data. All authors read the manuscript and provided their comments on the manuscript.

\section{Compliance with Ethical Standards}

Conflict of interest We declare no competing interests.

Open Access This article is distributed under the terms of the Creative Commons Attribution 4.0 International License (http://creativeco mmons.org/licenses/by/4.0/), which permits unrestricted use, distribution, and reproduction in any medium, provided you give appropriate credit to the original author(s) and the source, provide a link to the Creative Commons license, and indicate if changes were made.

\section{References}

Ayers JC, Goodbred S, George G, Fry D, Benneyworth L, Hornberger G, Roy K, Karim MR, Akter F (2016) Sources of salinity and arsenic in groundwater in southwest Bangladesh. Geochem Trans 17:1-22. https://doi.org/10.1186/s12932-016-0036-6 
Bangladesh Interactive Poverty Maps (2016) The World Bank Group. Accessed 10 Mar 2018

BBS (2015) Population and housing census 2011. Bangladesh Bureau of Statistics (BBS), Dhaka

BBS and UNICEF (2010) Multiple Indicator Cluster Survey (MICS) 2009, volume I: Technical Report. Bangladesh Bureau of Statistics (BBS) and UNICEF Bangladesh

BBS/WFP/IFAD (2012) Undernutrition Maps of Bangladesh 2012. Bangladesh Bureau of Statistics (BBS), World Food Programme (WFP), International Fund for Agricultural Development (IFAD), Dhaka, Bangladesh

BGS and DPHE (2001) Arsenic Contamination of Groundwater in Bangladesh, vol 2. Final Report WC/00/19. British Geological Survey (BGS) and Bangladesh Department of Public Health Engineering (DPHE), Keyworth

Bhattacharya P, Hossain M, Rahman SN, Robinson C, Nath B, Rahman M, Islam MM, Brömssen MV, Ahmed KM, Jacks G, Chowdhury D, Rahman M, Jakariya M, Persson LÅ, Vahter M (2011) Temporal and seasonal variability of arsenic in drinking water wells in Matlab, southeastern Bangladesh: a preliminary evaluation on the basis of a 4 year study. Environ Sci Health Part A 46:1177-1184

Burgess WG, Hoque MA, Michael HA, Voss CI, Breit GN, Ahmed KM (2010) Vulnerability of deep groundwater in the Bengal Aquifer System to contamination by arsenic. Nat Geosci 3:83-87. https:// doi.org/10.1038/ngeo 750

BWDB (2013) Hydrogeological study and mathematical modelling to identify sites for installation of observation well nest, vol 5 (Water Quality). Bangladesh Water Development Board (BWDB) and Institute of Water Modelling (IWM), Dhaka

Clasen TF, Alexander KT, Sinclair D, Boisson S, Peletz R, Chang HH, Majorin F, Cairncross S (2015) Interventions to improve water quality for preventing diarrhoea. Cochrane Database Syst Rev 10:CD004794. https://doi.org/10.1002/14651858.cd004794.pub3

Conti KI, Velis M, Antoniou A, Nijsten G-J (2016) Groundwater in the context of the Sustainable Development Goals: fundamental policy considerations. Brief for the UN Global Sustainable Development Report (GSDR) of 2016, IGRAC, Delft

Das S, Chandra H, Saha UR (2019) District level estimates and mapping of prevalence of diarrhoea among under-five children in Bangladesh by combining survey and census data. PLoS ONE 14:e0211062. https://doi.org/10.1371/journal.pone.0211062

Dhar RK, Zheng Y, Stute M, van Geen A, Cheng Z, Shanewaz M, Shamsudduha M, Hoque MA, Rahman MW, Ahmed KM (2008) Temporal variability of groundwater chemistry in shallow and deep aquifers of Araihazar, Bangladesh. J Contam Hydrol 99:97-111

DPHE (2016) Circlewise watre source status and coverage-June 2016. Department of Public Health Engineering (DPHE), Dhaka

DPHE/JICA (2010) Situation Analysis of Arsenic Mitigation 2009. Department of Public Health Engineering, Japan International Cooperation Agency Bangladesh, Dhaka

EPA (2018) 2018 edition of the drinking water standards and health advisories, EPA 822-F-18-001. U.S. Environmental Protection Agency, Washington

Fewtrell L, Kaufmann RB, Kay D, Enanoria W, Haller L, Colford JM $\mathrm{Jr}$ (2005) Water, sanitation, and hygiene interventions to reduce diarrhoea in less developed countries: a systematic review and meta-analysis. Lancet Infect Dis 5:42-52

Hanasaki N, Yoshikawa S, Pokhrel Y, Kanae S (2018) A global hydrological simulation to specify the sources of water used by humans. Hydrol Earth Syst Sci 22:789-817. https://doi.org/10.5194/ hess-22-789-2018

Hasan MK, Shahriar A, Jim KU (2019) Water pollution in Bangladesh and its impact on public health. Heliyon 5:e02145. https://doi. org/10.1016/j.heliyon.2019.e02145
Hassan MM, Atkins PJ (2007) Arsenic risk mapping in Bangladesh: a simulation technique of cokriging estimation from regional count data. J Environ Sci Health A Tox Hazard Subst Environ Eng 42:1719-1728

Khan JR, Bakar KS (2019) Targeting at risk households in Bangladesh exposed to arsenic contamination: a spatial analysis. Int J Environ Health Res. https://doi.org/10.1080/09603123.2019.1570488

Khan AE, Ireson A, Kovats S, Mojumder SK, Khusru A, Rahman A, Vineis P (2011) Drinking water salinity and maternal health in coastal Bangladesh: implications of climate change. Environ Health Perspect 119:1328-1332

Khan AE, Scheelbeek PFD, Shilpi AB, Chan Q, Mojumder SK, Rahman A, Haines A, Vineis P (2014) Salinity in drinking water and the risk of (pre)eclampsia and gestational hypertension in coastal Bangladesh: a case-control study. PLoS ONE 9:e108715. https:// doi.org/10.1371/journal.pone.0108715

MacDonald AM, Bonsor HC, Ahmed KM, Burgess WG, Basharat M, Calow RC, Dixit A, Foster SSD, Gopal K, Lapworth DJ, Lark RM, Moench M, Mukherjee A, Rao MS, Shamsudduha M, Smith L, Taylor RG, Tucker J, van Steenbergen F, Yadav SK (2016) Groundwater quality and depletion in the Indo-Gangetic Basin mapped from in situ observations. Nat Geosci 9:762-766

Mondal D, Ganguli B, Roy SS, Halder B, Banerjee N, Banerjee M, Samanta M, Giri AK, Polya DA (2014) Diarrhoeal health risks attributable to water-borne-pathogens in arsenic-mitigated drinking water in West Bengal are largely independent of the microbiological quality of the supplied water. Water 6:1100-1117

R Core Team (2017) R: a language and environment for statistical computing ( $\mathrm{R}$ version 3.4.3). R Foundation for Statistical Computing, Vienna. http://www.R-project.org/

Rahman AA, Ravenscroft P (eds) (2003) Groundwater resources and development in Bangladesh. The University Press Limited, Dhaka

Ravenscroft P (2003) Overview of the hydrogeology of Bangladesh. In: Rahman A, Ravenscroft P (eds) Groundwater resources development in Bangladesh. The University Press, Dhaka, pp 43-86

Ravenscroft P, McArthur JM, Hoque MA (2013) Stable groundwater quality in deep aquifers of Southern Bangladesh: the case against sustainable abstraction. Sci Total Environ 454-455:627-638

Rusydi AF (2018) Correlation between conductivity and total dissolved solid in various type of water: a review. IOP Conf Series Earth Environ Sci 118:012019. https://doi.org/10.1088/17551315/118/1/012019

Shamsudduha M (2018) Impacts of human development and climate change on groundwater resources in Bangladesh. In: Mukherjee A (ed) Groundwater of South Asia, vol Chapter 31. Springer Hydrogeology, Singapore, pp 523-544. https://doi. org/10.1007/978-981-10-3889-1_31

Shamsudduha M, Chandler RE, Taylor RG, Ahmed KM (2009) Recent trends in groundwater levels in a highly seasonal hydrological system: the Ganges-Brahmaputra-Meghna Delta. Hydrol Earth Syst Sci 13:2373-2385. https://doi.org/10.5194/hess-13-2373-2009

Shamsudduha M, Taylor RG, Longuevergne L (2012) Monitoring groundwater storage changes in the highly seasonal humid tropics: validation of GRACE measurements in the Bengal Basin. Water Resour Res 48:W02508. https://doi.org/10.1029/2011WR010993

Shamsudduha M, Zahid A, Burgess WG (2018) Security of deep groundwater against arsenic contamination in the Bengal Aquifer System: a numerical modeling study in southeast Bangladesh. Sustain Water Resour Manag. https://doi.org/10.1007/s4089 9-40018-40275-Z

Shamsudduha M, Joseph G, Haque SS, Khan MR, Zahid A, Ahmed KMU (2019) Multi-hazard groundwater risks to the drinking water supply in Bangladesh: challenges to achieving the sustainable development goals. Policy Research working paper WPS 8922. World Bank Group, Washington, DC 
Smith AH, Lingas EO, Rahman M (2000) Contamination of drinking water by arsenic in Bangladesh: a public health emergency. Bull World Health Organ 78:1093-1103

Stanaway JD, Afshin A, Gakidou E, Lim SS, Abate D, Abate KH, Abbafati C, Abbasi N, Abbastabar H, Abd-Allah F, Abdela J (2018) Global, regional, and national comparative risk assessment of 84 behavioural, environmental and occupational, and metabolic risks or clusters of risks for 195 countries and territories, 1990-2017: a systematic analysis for the Global Burden of Disease Study 2017. Lancet 10159:1923-1994

Taylor RG, Scanlon B, Doll P, Rodell M, van Beek R, Wada Y, Longuevergne L, Leblanc M, Famiglietti JS, Edmunds M, Konikow L, Green TR, Chen J, Taniguchi M, Bierkens MFP, MacDonald A, Fan Y, Maxwell RM, Yechieli Y, Gurdak JJ, Allen DM, Shamsudduha M, Hiscock K, Yeh PJF, Holman I, Treidel H (2013) Ground water and climate change. Nat Clim Change 3:322-329. https://doi.org/10.1038/nclimate1744

UNICEF (2010) WASH Technology Information Packages for UNICEF WASH Programme and Supply Personnel. UNICEF and Skat-Swiss Resource Centre and Consultancies for Development, Copenhagen

UNICEF and BBS (2015) Bangladesh Multiple Indicator Cluster Survey (MICS) 2012-2013. Vol Ref. BGD_2012_MICS_v01_M. United Nations Children's Fund, Bangladesh Bureau of Statistics, New York

van Geen A, Ahmed KM, Ahmed EB, Choudhury I, Mozumder MR, Bostick BC, Mailloux BJ (2016) Inequitable allocation of deep community wells for reducing arsenic exposure in Bangladesh. J Water Sanit Hyg Dev 6:142-150. https://doi.org/10.2166/washd ev.2015.115
WHO (2011) Guidelines for drinking-water quality. World Health Organization, Geneva

WHO/UNICEF (2019) Progress on drinking water, sanitation and hygiene: 2019 update and SDG baselines. World Health Organization (WHO) and the United Nations Children's Fund (UNICEF), Geneva

Wolf J, Hunter PR, Freeman MC, Cumming O, Clasen T, Bartram J, Higgins JPT, Johnston R, Medlicott K, Boisson S, Prüss-Ustün A (2018) Impact of drinking water, sanitation and handwashing with soap on childhood diarrhoeal disease: updated meta-analysis and meta-regression. Tropical Med Int Health 23:508-525

World Bank (2018) Precarious progress: a diagnostic of water supply, sanitation, hygiene, and poverty in Bangladesh. World Bank, Washington

Zahid A, Jahan K, Ali MH, Ahmed N, Islam MK, Rahman A (2013) Distribution of groundwater salinity and its seasonal variability in the Coastal aquifers of Bengal Delta. In: Zahid A, Hassan MQ, Islam R, Samad QA, Khan MS, Haque R (eds) Impact of climate change on socio-economic conditions of Bangladesh. Alumni Association of German Universities in Bangladesh, German Academic Exchange Service (DAAD), Dhaka, pp 170-193

Publisher's Note Springer Nature remains neutral with regard to jurisdictional claims in published maps and institutional affiliations. 